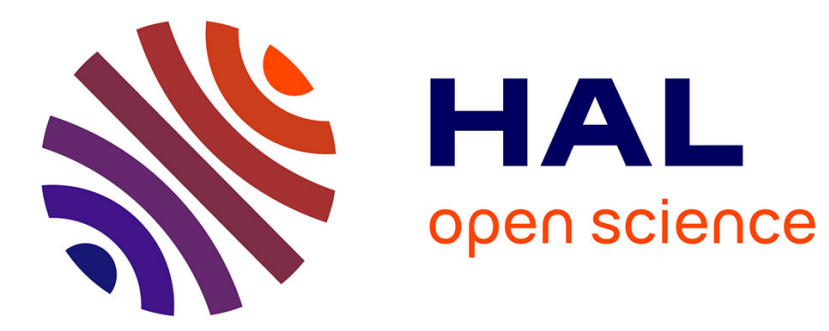

\title{
Impact of thermal energy storage integration on the performance of a hybrid solar gas-turbine power plant
}

\author{
B. Grange, C. Dalet, Q. Falcoz, A. Ferrière, G. Flamant
}

\section{To cite this version:}

B. Grange, C. Dalet, Q. Falcoz, A. Ferrière, G. Flamant. Impact of thermal energy storage integration on the performance of a hybrid solar gas-turbine power plant. Applied Thermal Engineering, 2016, 105, pp.266 - 275. 10.1016/j.applthermaleng.2016.05.175 . hal-03368107

\section{HAL Id: hal-03368107 https://hal.science/hal-03368107}

Submitted on 6 Oct 2021

HAL is a multi-disciplinary open access archive for the deposit and dissemination of scientific research documents, whether they are published or not. The documents may come from teaching and research institutions in France or abroad, or from public or private research centers.
L'archive ouverte pluridisciplinaire HAL, est destinée au dépôt et à la diffusion de documents scientifiques de niveau recherche, publiés ou non, émanant des établissements d'enseignement et de recherche français ou étrangers, des laboratoires publics ou privés. 
Research Paper

\title{
Impact of thermal energy storage integration on the performance of a hybrid solar gas-turbine power plant
}

\author{
B. Grange, C. Dalet, Q. Falcoz*, A. Ferrière, G. Flamant \\ PROMES-CNRS Laboratory, 7 rue du Four Solaire, 66120 Font Romeu, France
}

\section{H I G H L I G H T S}

- We model two hybrid solar gas turbine power plants.

- We compare different operating strategies.

- We evaluate the influence of the heat storage integration.

- The heat storage integration induces a high and stable electrical production.

\section{A R T I C L E I N F O}

\section{Article history:}

Received 21 December 2015

Revised 26 May 2016

Accepted 29 May 2016

Available online 30 May 2016

\section{Keywords}

Hybrid solar gas-turbine power plant

Concentrated solar power

Thermal energy storage

Systemic model

Design optimization

\begin{abstract}
A B S T R A C T
The interest for hybrid solar gas-turbine systems (HSGT) in solar power tower plant technologies is growing. This is due to the high conversion efficiency and to the low water consumption that are achieved when a combined cycle is implemented. This paper presents a simulation tool which is dedicated to the performance analysis a hybrid solar gas turbine solar plant featuring a thermal energy storage (TES) unit. This study is conducted within the framework of the French PEGASE project (Production of Electricity from Gas and Solar Energy) which aims at setting up and testing at THEMIS site (France) a demonstration plant based on HSGT technology. The TES unit called packed bed consists in a cylindrical tank filled with spherical rocks. For a given gas-turbine, the designs of the storage and the heliostat field are carried out. Depending on the operating strategy, this work establishes that the integration of a TES unit offers a higher and more stable electrical generation. The TES unit increases, in some case drastically, the daily average solar share of the power plant. Finally it leads to a higher electrical production per unit of fuel consumed.
\end{abstract}

(c) 2016 Elsevier Ltd. All rights reserved.

\section{Introduction}

Compared to fossil fuels, renewable energy resources present an inherent disadvantage: their intermittent nature. However concentrated solar power (CSP) [1] is a very attractive electricity generation technology, compared to other renewable electricity generation systems, because of its ability to incorporate a gas turbine. With a gas turbine technology, a hybrid operation ensures a dispatchable power [2]. However conventional gas turbine power plants do not have a real ability for the integration of another intermittent energy source [3]. A technical challenge due to the hybridization is the adaptation of the combustion chamber to a large range of fuel air ratio (FAR).

\footnotetext{
* Corresponding author.

E-mail address: quentin.falcoz@promes.cnrs.fr (Q. Falcoz).
}

Camacho et al. [4,5] proposed advanced control techniques applied to a global CSP system simulation in order to solve the problems due to the sporadic solar radiation. These techniques generally focus on the heat transfer fluid flow rate as an actuator to adjust the solar outlet collector temperature [6].

Another solution to stabilize the temperature at the combustion chamber inlet - thereby to reduce its FAR operating range - is to incorporate a large-scale thermal energy storage (TES). This option provides a high potential for the penetration of CSP in the existing grid [7]. The added value of TES technology in CSP systems has been well demonstrated by previous research through a state of the art on high temperature TES for power generation focusing on concepts, materials and simulation [8]. To achieve a better understanding of the behavior of TES coupled with CSP systems, a comprehensive analysis should be undertaken $[9,10]$. The present work intends to contribute to this analysis. 


\begin{tabular}{|c|c|c|c|}
\hline \multicolumn{4}{|c|}{ Nomenclature } \\
\hline A & area $\left(\mathrm{m}^{2}\right)$ & $\eta$ & efficiency $(-)$ \\
\hline c & specific heat capacity $(\mathrm{J} / \mathrm{kg} \mathrm{K})$ & $\mu$ & dynamic viscosity (Pa s) \\
\hline$c_{n}$ & molar heat capacity $(\mathrm{J} / \mathrm{mol} \mathrm{K})$ & $\rho$ & density $\left(\mathrm{kg} / \mathrm{m}^{3}\right)$ \\
\hline$d_{p}$ & particle diameter $(\mathrm{m})$ & $\sigma$ & tensile stress $(\mathrm{Pa})$ \\
\hline $\mathrm{D}$ & diameter $(\mathrm{m})$ & $\tau_{\text {sol }}$ & solar share $(-)$ \\
\hline G & mass flow per unit cross section $\left(\mathrm{kg} / \mathrm{m}^{2} \mathrm{~s}\right)$ & & \\
\hline $\mathrm{H}$ & enthalpy (W) & Indices & \\
\hline $\mathrm{h}_{\mathrm{v}}$ & volumetric heat transfer coefficient $\left(\mathrm{W} / \mathrm{m}^{3} \mathrm{~K}\right)$ & $\mathrm{CCh}$ & combustion chamber \\
\hline $\mathrm{k}$ & thermal conductivity $(\mathrm{W} / \mathrm{m} \mathrm{K})$ & comp & compressor \\
\hline $\mathrm{k}_{\mathrm{s}, \mathrm{eff}}$ & $\begin{array}{l}\text { effective thermal conductivity of the packed bed (W/ } \\
\mathrm{m} \mathrm{K} \text { ) }\end{array}$ & $\begin{array}{l}\text { dis } \\
\text { elec }\end{array}$ & $\begin{array}{l}\text { discharge } \\
\text { electrical }\end{array}$ \\
\hline $\mathrm{L}$ & length $(\mathrm{m})$ & exp & expander \\
\hline $\mathrm{m}$ & mass $(\mathrm{kg})$ & f & fluid \\
\hline$\dot{m}$ & mass flow $(\mathrm{kg} / \mathrm{s})$ & in & inlet \\
\hline$\dot{n}$ & molar flow $(\mathrm{mol} / \mathrm{s})$ & $\max$ & maximal value \\
\hline $\mathrm{P}_{\text {rel }}$ & relative pressure $(\mathrm{Pa})$ & mir & mirror \\
\hline Q & energy $(\mathrm{J})$ & out & outlet \\
\hline$\dot{Q}$ & power $(\mathrm{W})$ & receiv & solar receiver \\
\hline $\mathrm{R}$ & radius $(\mathrm{m})$ & $\mathrm{s}$ & solid \\
\hline $\mathrm{t}$ & thickness (m) & SF & solar field \\
\hline $\mathrm{t}$ & time $(s)$ & SR & solar receiver \\
\hline $\mathrm{T}$ & temperature $(\mathrm{K})$ & stor & storage \\
\hline $\mathrm{U}$ & $\begin{array}{l}\text { overall heat transfer coefficient through the wall (W/ } \\
\left.\mathrm{m}^{2} \mathrm{~K}\right)\end{array}$ & Acronym & \\
\hline W & work $(\mathrm{W})$ & CSP & concentrated solar power \\
\hline $\mathrm{x}_{\mathrm{i}}$ & molar fraction $(-)$ & DNI & Direct Normal Irradiance \\
\hline$\Delta_{\mathrm{f}} \mathrm{H}$ & standard enthalpy of formation $(\mathrm{J} / \mathrm{mol})$ & EPTFC & electrical production per ton of fuel consumed \\
\hline$\Delta_{\mathrm{R}} \mathrm{H}$ & standard enthalpy of reaction (J/mol) & FAR & fuel-air ratio \\
\hline$\Delta \mathrm{P}$ & pressure loss $(\mathrm{Pa})$ & HSGTPP & hybrid solar gas-turbine power plant \\
\hline$\delta$ & compression/expansion rate $(-)$ & PEGASE & Production of Electricity from Gas and Solar Energy \\
\hline$\varepsilon$ & porosity $(-)$ & TES & thermal energy storage \\
\hline$\gamma$ & $\begin{array}{l}\text { fluid isentropic coefficient during compression/expan- } \\
\text { sion (-) }\end{array}$ & & \\
\hline
\end{tabular}

Most of the existing simulation works are dedicated to the parabolic trough technology. Experiments with molten salt tower technology at Themis (France, 1986), Solar Two (USA, 2000), and more recently at Gemasolar (Spain, 2010) have demonstrated the added value created by molten salt TES in the case of a solar tower plant [11]. But no system analysis based on simulation work has been published so far.

A few global simulation tools allow modeling different solar power plant technologies such as parabolic trough, salt tower or HSGT. A CSP performance model was recently developed by NREL and Sandia National Laboratory and was implemented in SAM (System Advisor Model) [12]. NREL has developed a "generic solar system" performance model for use in SAM. In this tool, the TES component is modeled using a simple energy-balance approach. Giuliano et al. [13] evaluated the performance of solar thermal power plants with TES featuring a hybrid solar operation strategy on an annual basis. Different CSP technologies (solar-hybrid combined cycle, salt tower, parabolic trough, $\mathrm{CO}_{2}$-tower, particle receiver tower with combined cycle) were investigated with different sizes of solar fields and different storage capacities. The commercial software Ebsilon was used for simulating the operation of the plant. The results showed that the potential to reduce the $\mathrm{CO}_{2}$ emission is high for solar thermal plants operated in baseload with high storage capacities.

This paper deals with the development of a global simulation tool dedicated to an innovative technology: a hybrid solar-gas turbine power plant (HSGTPP) integrating a TES unit. The TES unit consists in a cylindrical packed bed of spherical rocks. For a given gas-turbine, the influence of the TES on the performance of the combustion chamber - and thereby on the power plant production - is examined for three operating strategies and two solar irradiance variations. This study takes place within the framework of the French PEGASE project (Production of Electricity from Gas and Solar Energy) which aims at setting up and testing at THEMIS site (French Pyrenees) a solar demonstration plant based on HSGT technology [14].

\section{System description}

\subsection{Technology of the power plant}

The HSGTPP considered in this study features a solar heliostat field and a tower. The power block is located at the top of the tower. It is made up of a compressor, a pressurized air solar receiver, a combustion chamber fed with natural gas $\left(\mathrm{CH}_{4}\right)$ and an expander coupled to an electrical power generator. In this system, pressurized air is the heat transfer fluid and is the working fluid as well. Two options are considered: the power plant without and with a sensible TES unit (part surrounded by a dotted rectangle in Fig. 1). Without the storage system, the plant is operated as follow: after being compressed, the air is heated up in a solar receiver and can reach temperature up to $1000{ }^{\circ} \mathrm{C}$ depending on the receiver material used. Then a combustion chamber allows stabilizing 


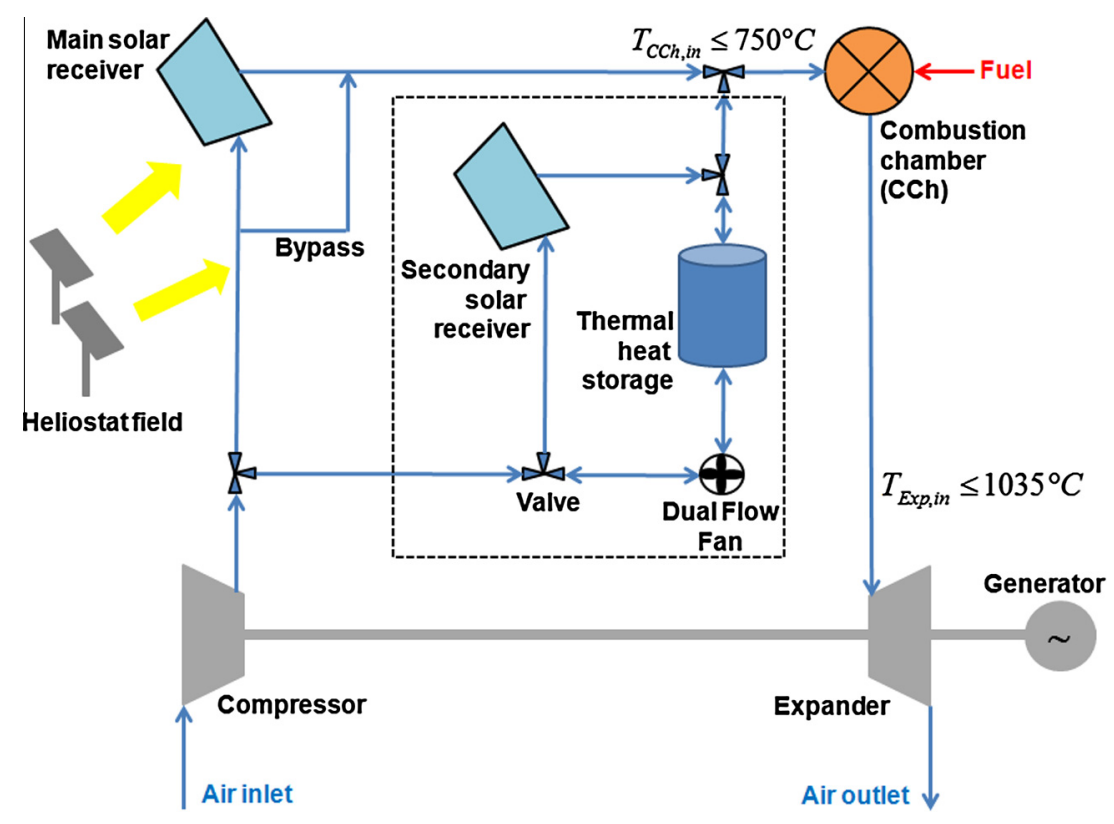

Fig. 1. Scheme of the HSGTPP with TES (dotted square considered) and without TES (dotted square not considered).

the temperature required at the inlet of the expander. Finally the hot compressed air drives the expander. A part of the mechanical power produced in the expander is used to run the compressor which is on the same shaft.

The solar receiver that is developed in the PEGASE project [14] consists in a metallic surface absorber located at the back of a cavity. Therefore the maximum air temperature at the inlet of the combustion chamber is limited by the receiver's technology and set to $750{ }^{\circ} \mathrm{C}$. Without a TES unit, if the solar incident power is too high and would provide a higher air temperature, the heliostat field is partly defocused.

With the TES unit, a secondary solar receiver is added. The operating mode of the storage (idle, charging, discharging) is selected by comparing the air temperature at the main solar receiver outlet with the maximum temperature at the combustion chamber inlet $\left(\mathrm{T}_{\mathrm{CCh}, \mathrm{in}, \mathrm{max}}\right)$ and by considering the storage status. When charging, the storage is considered full when the air temperature at its outlet (bottom of the TES unit in Fig. 1) reaches $400^{\circ} \mathrm{C}$. This choice allows the preservation of an optimal efficiency of the fan and prevents it from any damage. The air mass flow-rate in the compressor and in the combustion chamber inlet remains constant in the three following operating modes.

\subsubsection{Main receiver only operating mode}

TES is idle in this mode. Two situations are considered:

- The storage is empty and the solar resource is insufficient or just sufficient enough to achieve the air temperature $\mathrm{T}_{\mathrm{CCh}, \mathrm{in}, \max }$ at the outlet of the main receiver.

- The storage is full and the air temperature $T_{\mathrm{CCh}, \text { in,max }}$ is achieved at the outlet of the main receiver. The solar field might be partly defocused in order to keep the air temperature at $\mathrm{T}_{\mathrm{CCh}, \text { in,max }}$.

\subsubsection{Storage charging}

The solar incident power is too high for the main solar receiver and the storage is not full. The heliostat field is partly focused on the secondary solar receiver. The mass flow-rate through the secondary solar receiver is adjusted in order to keep $\mathrm{T}_{\mathrm{CCh} \text {,in,max }}$ at its outlet. The air flows from the top to the bottom of the storage, transferring the heat to the storage made of a packed bed of spher- ical rocks inserted in a metallic cylindrical tank. To overcome the pressure drop in both the secondary solar receiver and the storage, a fan is used to push the air from the storage back into the secondary solar receiver.

\subsubsection{Storage discharging}

When the storage maximum temperature is higher than the air temperature at the outlet of the main solar receiver, a part of the mass flow-rate at the outlet of the compressor is directed to the storage, flowing from the bottom to the top.

Thus the main receiver is partially or fully by-passed, according to the solar irradiation and the temperature profile within the storage.

\subsection{Design of the power plant}

The HSGTPP's design is carried out by considering the PEGASE project objective, which is to operate a $1.4 \mathrm{MW}_{\mathrm{e}}$ gas-turbine. Table 1 presents the characteristics of the selected gas-turbine.

In the framework of Mini-Pegase, a prototype (1/10) of solar receiver has been designed, for a thermal power of $360 \mathrm{~kW}_{\mathrm{th}}$. A solar receiver model [15] achieves a thermal efficiency around 80 $\%$ at nominal operating conditions. In this paper, it is assumed that the thermo-hydraulic performance of the full-scale solar receiver and of the pilot-scale solar receiver is similar.

To design the TES unit, a characteristic discharge time of $5 \mathrm{~h}$ is set for a thermal power of $3.6 \mathrm{MW}_{\mathrm{th}}$. Therefore the heat capacity of the storage is $64.8 \mathrm{GJ}$. Then by considering a temperature difference in the storage of $400{ }^{\circ} \mathrm{C}$, a thermal efficiency of $90 \%$ and the properties of the selected rocks (steatite) presented in Table 2 , the volume of solid is equal to $67 \mathrm{~m}^{3}$.

Table 1

Design point parameters of the selected gas-turbine.

\begin{tabular}{lll}
\hline & Kawasaki M1A-13X & \\
\hline Shaft power & 1.43 & $\left(\mathrm{MW}_{\mathrm{e}}\right)$ \\
Shaft efficiency & 23.6 & $(\%)$ \\
Firing temperature & 1035 & $\left({ }^{\circ} \mathrm{C}\right)$ \\
Pressure ratio & 9.6 & $(-)$ \\
Exhaust mass flow & 7.94 & $(\mathrm{~kg} / \mathrm{s})$ \\
Exhaust gas temperature & 524 & $\left({ }^{\circ} \mathrm{C}\right)$ \\
\hline
\end{tabular}


Table 2

Properties of steatite.

\begin{tabular}{lll}
\hline & Steatite & \\
\hline Density, $\rho_{\mathrm{s}}$ & 2700 & $\left(\mathrm{~kg} / \mathrm{m}^{3}\right)$ \\
Specific heat capacity, $\mathrm{c}_{\mathrm{s}}$ & 1000 & $(\mathrm{~J} / \mathrm{kg} \mathrm{K})$ \\
Thermal conductivity, $\mathrm{k}_{\mathrm{s}}$ & 2.5 & $(\mathrm{~W} / \mathrm{m} \mathrm{K})$ \\
\hline
\end{tabular}

According to Zou and $\mathrm{Yu}$ [16], the porosity $\varepsilon$ (fraction of the volume of voids over the total volume) of a packed bed of spherical rocks in a cylindrical tank is calculated as follow:

$\varepsilon=0.372+0.002\left(e^{15.306 d_{p} / D}-1\right)$

With $d_{p}$ and $D$ the diameter of the particles and the tank, respectively (m). This equation is valid for $D / d_{p}>3.95$.

In our case, as the diameter of the particle is much smaller than the one of the tank, the porosity is 0.372 , resulting in a tank of $106 \mathrm{~m}^{3}$. Then the correlations developed by Hänchen et al. [17] provide the volumetric heat transfer coefficient $h_{v}$ and the pressure drop $\Delta \mathrm{P}$.

$h_{v}=700 G^{0.76} d_{p}^{-0.76}$

With $\mathrm{G}$ the mass flow per unit cross section $\left(\mathrm{kg} / \mathrm{m}^{2} \mathrm{~s}\right)$.

$\Delta P=\frac{L G^{2}}{\rho_{f} d_{p}}\left(1.75 \frac{1-\varepsilon}{\varepsilon^{3}}+150 \frac{(1-\varepsilon)^{2}}{\varepsilon^{3}} \frac{\mu_{f}}{G d_{p}}\right)$

With $\mathrm{L}$ the height of the storage $(\mathrm{m}), \rho_{\mathrm{f}}$ the density of the fluid $\left(\mathrm{kg} / \mathrm{m}^{3}\right)$ and $\mu_{\mathrm{f}}$ the dynamic viscosity of the fluid (Pa s).

A tradeoff between the volumetric heat transfer coefficient and the pressure drop leads to a cylindrical tank with a $15 \mathrm{~m}$ height and a $3 \mathrm{~m}$ diameter. However, to keep the air temperature leaving the bottom of the storage unit below $400^{\circ} \mathrm{C}$, the storage tank is oversized by $10 \%$ resulting in the same diameter but a height of $16.5 \mathrm{~m}$. At nominal operating conditions, the total pressure drop is $77 \mathrm{mbar}$ and the volumetric heat transfer coefficient is around $15,000 \mathrm{~W} / \mathrm{m}^{3} \mathrm{~K}$.

Finally the design of the heliostat field is dependent on the storage integration. For a HSGTPP without a TES unit, the heliostat field should deliver enough solar incident power to transfer 3.6 $\mathrm{MW}_{\text {th }}$ to the pressurized air. To do so, a nominal optical efficiency of $80 \%$ and a receiver nominal thermal efficiency of $80 \%$ are considered. Moreover the nominal solar irradiation of the THEMIS site (Targasonne, France) is set to $1000 \mathrm{~W} / \mathrm{m}^{2}$. Therefore, the total reflective surface for the HSGTPP without a TES unit is $5625 \mathrm{~m}^{2}$, resulting in 104 heliostats of $54 \mathrm{~m}^{2}$ (surface of the THEMIS heliostats). For a HSGTPP with a TES unit, the reflective surface is doubled, leading to a field of 208 heliostats of $54 \mathrm{~m}^{2}$

\section{Modeling tool}

\subsection{Model principle}

A systemic and pseudo-dynamic approach is developed and is based on energy balance through enthalpy. The pseudo-dynamic model calculates the thermodynamic equilibrium states for each time step ( $1 \mathrm{~min})$, without considering the transient modes. It allows evaluating the fluid transformation (in term of composition, temperature and pressure change) through each component by using simple energy and mass balances. The mass and energy balances determine the gap between the actual fluid transformation and the ideal one (transformation for an ideal component). Each component is characterized by its efficiency $(\eta)$. The air temperature at the outlet of each component is calculated by applying an enthalpy balance and taking into account the efficiency of the component.

The enthalpy is written as follow:

$\mathrm{H}=\dot{\mathrm{n}} \sum_{\mathrm{i}=1}^{\mathrm{N}} \mathrm{X}_{\mathrm{i}}\left(\Delta_{\mathrm{f}} \mathrm{H}_{\mathrm{i}}+\int_{\mathrm{T}^{\circ}}^{\mathrm{T}} \mathrm{c}_{\mathrm{n}, \mathrm{i}} \mathrm{dT}\right) \quad(\mathrm{W})$

With $\mathrm{n}$ the molar flow $(\mathrm{mol} / \mathrm{s}), \mathrm{x}_{\mathrm{i}}$ the molar fraction of the species $\mathrm{i}$ $(-), \Delta_{\mathrm{f}} \mathrm{H}_{\mathrm{i}}$ the standard enthalpy of the species $\mathrm{i}$ at the reference temperature $\mathrm{T}^{\circ}(\mathrm{J} / \mathrm{mol})$ and $\mathrm{c}_{\mathrm{n}, \mathrm{i}}$ the heat capacity of the species $\mathrm{i}$ at constant pressure $(\mathrm{J} / \mathrm{mol} \mathrm{K})$.

\section{Model hypotheses}

- All components are adiabatic.

- The heat and pressure losses through the pipes are neglected.

\section{Model inputs}

The components' performance, $\eta$, is a function of their design parameters (technology and size) and of the operating conditions. In the systemic approach, the boundary operating conditions of each component is taken into account.

To summarize, there are two kinds of input:

- the components characteristics (efficiency, boundaries operating conditions);

- the evolution of the ambient conditions (ambient temperature and pressure, solar irradiation).

\section{Performance's parameters}

The model evaluates the performance of the power plant as a function of the operating conditions. The power plant performance is determined using three criteria: the solar fraction, the electrical production and the electrical production per ton of fuel consumed (EPTFC).

The solar fraction estimates the solar contribution to the total heat provided to the fluid. It comes directly from the solar receiver and from the storage when it is discharging. Consequently, the solar fraction is written as,

$\tau_{\text {sol }}=\left(\mathrm{Q}_{\text {receiv }}+\mathrm{Q}_{\text {dis }}\right) /\left(\mathrm{Q}_{\text {receiv }}+\mathrm{Q}_{\text {dis }}+\mathrm{Q}_{\mathrm{cch}}\right) \quad(-)$

With $Q_{i}$ the amount of heat provided to fluid by the component $i$ during one time step $\Delta t(\mathrm{~J})$.

The electrical production is calculated as follow:

$\dot{Q}_{\text {elec }}=\eta_{\text {elec }}\left(W_{\text {exp }}-W_{\text {comp }}\right) \cdot t_{\text {operating }}$

With $\eta_{\text {elec }}$ the generator efficiency (-), $\mathrm{W}_{\text {exp }}$ the mechanical power provided by the expander to the shaft $(\mathrm{W}), \mathrm{W}_{\text {comp }}$ the mechanical power provided by the shaft to the compressor $(\mathrm{W})$ and $\mathrm{t}_{\text {operating }}$ the operating time interval $(\mathrm{h})$.

The electrical production per ton of fuel consumed is calculated using Eq. (7).

$E P T F C=\frac{\overline{\dot{Q}_{\text {elec }}}}{m_{\text {fuel }}} \quad(\mathrm{W} \mathrm{h/t})$

With $\overline{\dot{Q}_{\text {elec }}}$ the average electrical production $(\mathrm{Wh})$ and $\mathrm{m}_{\text {fuel }}$ the amount of fuel consumed (ton).

\subsection{Solar system}

The solar flux impacting on the solar receiver surface depends on the solar resource (DNI), the sun position and the different losses between the solar field and the receiver.

The solar power impacting on the receiver surface is calculated from an efficiency matrix of the solar field $\left(\eta_{S F}\right)$ given by Garcia [14], the Direct Normal Irradiance (DNI) and the area of the reflective surface $\left(A_{\text {mir }}\right)$ : 
$\dot{Q}_{\mathrm{SF}}=\eta_{\mathrm{SF}} \cdot \mathrm{DNI} \cdot \mathrm{A}_{\mathrm{mir}}(\mathrm{W})$

The heat quantity transferred to the fluid through the solar receiver depends on the receiver efficiency $\eta_{R}$. The receiver efficiency is given by a model of a pilot-scale solar receiver designed for a $750{ }^{\circ} \mathrm{C}$ outlet air temperature [15]. The hydraulic and thermal performances of the receiver's modules are based on experimental results [18]. The thermal efficiency of the receiver is a function of the solar flux $\left(\mathrm{P}_{\mathrm{SF}}\right)$ intercepted by the solar receiver, the air temperature at the inlet of the receiver and the air mass flow-rate. The pressure loss in the receiver depends on the air mass flow-rate.

The enthalpy variation of the fluid through the receiver is calculated as follow:

$\Delta \mathrm{H}=\eta_{\text {receiv }} \dot{\mathrm{Q}}_{\mathrm{SF}} \quad(\mathrm{W})$

With $\eta_{\text {receiv }}$ the receiver efficiency (-).

\subsection{Gas turbine}

The isentropic efficiency allows the performance assessment of the compressor and the turbine. They are respectively expressed for perfect gas as follow [19]:

$\eta_{\text {comp }}=\frac{\left[T_{\text {comp }, \text { in }}\left(\delta_{\text {comp }}^{(\gamma-1) / \gamma}-1\right)\right]}{\left(T_{\text {comp }, \text { out }}-T_{\text {comp }, \text { in }}\right)} \quad(-)$

$\eta_{\exp }=\frac{\left(T_{\text {exp }, \text { out }}-T_{\text {exp }, \text { in }}\right)}{\left[T_{\exp , \text { in }}\left(\delta_{\exp }^{(\gamma-1) / \gamma}-1\right)\right]} \quad(-)$

$\delta_{\text {comp }}$ and $\delta_{\text {exp }}$ are the compression and the expansion rates, respectively (-). $\gamma$ is the fluid isentropic coefficient during the compression or the expansion. It is expressed as the ratio between the heat capacity of the fluid at constant pressure and the one at constant volume. The isentropic coefficient used in Eqs. (10) and (11) is the mean value between the isentropic coefficients of the fluid at its inlet and outlet temperatures. In the model, the outlet temperatures of the fluid are unknown. Consequently, an iterative method is used in order to determine the outlet temperature from the isentropic efficiency of the compressor or of the turbine.

The combustion efficiency is the characteristic parameter of the combustion chamber to calculate the enthalpy balance. It estimates in what way the combustion is complete. It is defined as the ratio of the actual amount of heat released by the reaction to the ideal one. The ideal enthalpy of reaction is equal to the heat produced if the reaction is complete and is calculated with the low heating value (LHV). The actual amount of heat released by the reaction $\Delta_{R} \mathrm{H}$ is determined assuming that:

- the combustion is considered adiabatic (all the heat amount released by the reaction participates to the rise of the products' temperature), which means that the enthalpy variation of the species between the inlet and the outlet of the combustion chamber is equal to zero,

- the stoichiometric coefficients of all the species participating in the reaction (including the nitrogen) are taking into account.

The combustion efficiency can be written as follow:

$\eta_{\text {cch }}=\frac{\Delta_{\mathrm{R}} \mathrm{H}}{\Delta_{\mathrm{R}} \mathrm{H}_{\text {ideal }}} \quad(-)$

The value of the combustion efficiency depends on the operating conditions of the combustion chamber. A combustion chamber is usually designed for a given fuel-air ratio range. Within this range, the combustion efficiency is closed to 1 . However outside this range, the combustion efficiency can decrease drastically. In the model, the combustion efficiency is supposed to be equal to

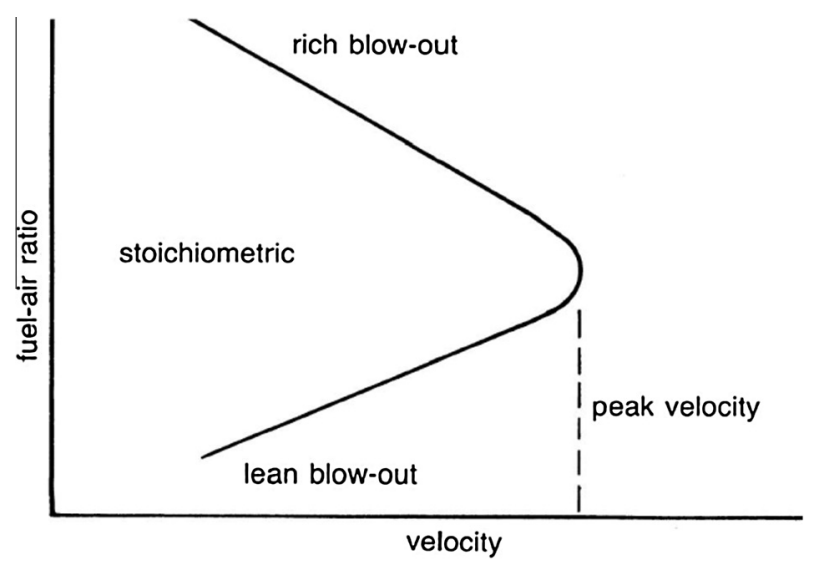

Fig. 2. Range of burnable fuel-air ratios versus gas velocity [19].

1 within the fuel-air ratio range for which the combustion chamber is designed (from 0.0175 to 0.04 in this paper) and equal to 0 outside this range. Nevertheless, new design of combustion chamber has to be carried out to accept this large range of FAR. Indeed if the air inlet temperature is higher than the one expected in conventional gas turbine, the amount of fuel needed to reach $1000{ }^{\circ} \mathrm{C}$ at the turbine inlet is too low to guarantee the flame stability. With the high velocity of the air due to a lower density, a flame blowing is likely to occur. Fig. 2, extracted from [19], is a general stability diagram which shows the evolution of the range of burnable mixture.

\subsection{Storage}

The storage model relies on the work carried out by Hächen et al. [17]. The governing unsteady energy conservation equations are:

- For the fluid phase:

$\frac{\partial T_{f}}{\partial t}+\frac{G}{\rho_{f} \varepsilon} \frac{\partial T_{f}}{\partial x}=\frac{h_{v}}{\rho_{f} c_{f} \varepsilon}\left(T_{s}-T_{f}\right)+\frac{U D \pi}{\rho_{f} c_{f} A \varepsilon}\left(T_{\infty}-T_{f}\right)$

- For the solid phase:

$\frac{\partial T_{s}}{\partial t}=\frac{h_{v}}{\rho_{s} c_{s}(1-\varepsilon)}\left(T_{f}-T_{s}\right)+\frac{k_{s, e f f}}{\rho_{s} c_{s}(1-\varepsilon)} \frac{\partial^{2} T}{\partial x^{2}}$

Eqs. (13) and (14) are discretized by applying the implicit forward method in time and the upwind difference scheme in space. The thermo and hydraulic performances of the storage are given by Eqs. (2) and (3). The time and space intervals are $1 \mathrm{~min}$ and $10 \mathrm{~cm}$, respectively. At the beginning of the simulation, the initial temperature of the solid and the fluid is set to $300^{\circ} \mathrm{C}$. Then for each time step, the initial temperature profile corresponds to the one calculated at the previous time step.

\section{Strategies and model sequence}

\subsection{Power plant operating strategies}

Three different operating strategies of the HSGTPP, without and with a TES unit, are compared in this study:

a. A base-load power plant, providing a $24 \mathrm{~h} / 24 \mathrm{~h}$ electrical production.

b. A load following power plant, responding to a load curve chosen from 9 a.m. to 11 p.m. 


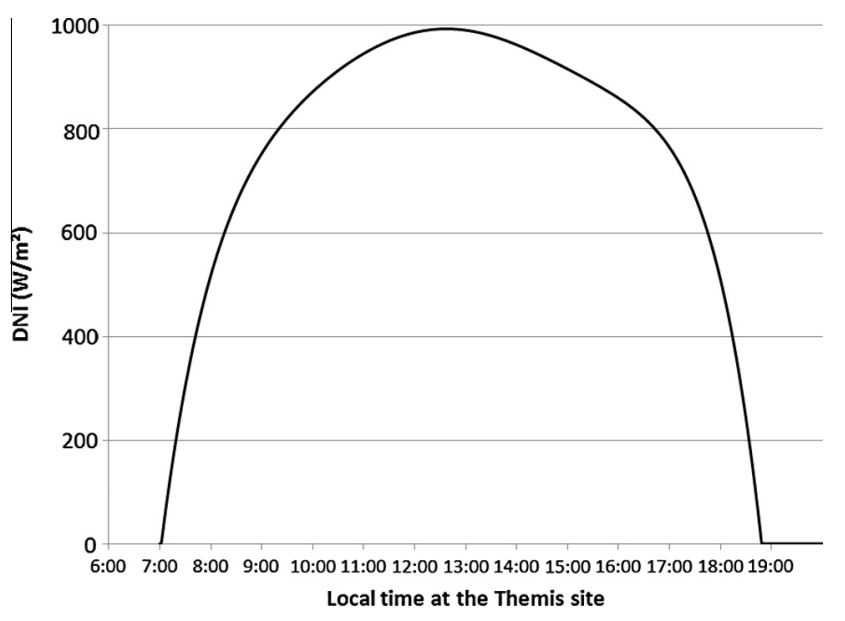

Fig. 3. DNI variation - 29th of March.

c. An electrical production when the inlet temperature in the expander is equal to the design inlet temperature.

\subsection{Typical day}

The simulations are carried out for two different DNI variations. First a typical sunny day is considered. The graph presented in Fig. 3 comes from DNI data at the THEMIS site the 29th of March.
The corresponding ambient temperatures are inserted in the input data of the model and range from $5^{\circ} \mathrm{C}$ and $19^{\circ} \mathrm{C}$.

For the second case, the DNI variation of Fig. 3 is still used, but the DNI drops down to zero at noon and stay at zero, corresponding to a sunny morning and a cloudy afternoon.

\subsection{Model sequence}

To clarify the different storage operating modes and the model sequence, Fig. 4 presents the flowchart of the HSGTPP with TES.

After reading the input data for each time step, the power reaching the solar receiver is calculated through the solar field efficiency $\eta_{\text {SF. }}$. The air temperature at the solar receiver inlet is calculated through the isentropic efficiency of the compressor $\eta_{\text {comp. }}$. The air temperature at the solar receiver outlet is evaluated using the solar receiver efficiency $\eta_{\mathrm{SR}}$. Depending on this temperature and on the storage temperature profile, the storage is idle, charged or discharged. When the storage is charged or discharged, the new storage temperature profile is calculated by running the storage model.

If the power plant is following the strategy (a), the air leaving the main solar receiver always goes through the combustion chamber and drives the expander. If strategy (b) is chosen, the storage will be charged until 9 a.m., then the power plant operates the same way as in strategy (a) until 11 p.m. Finally with strategy (c), the expander is idle if the design temperature at its inlet cannot be reached, limited by the maximum value of the FAR. In that case, the solar incident power can be used to heat the air through the secondary solar receiver in order to charge the storage.

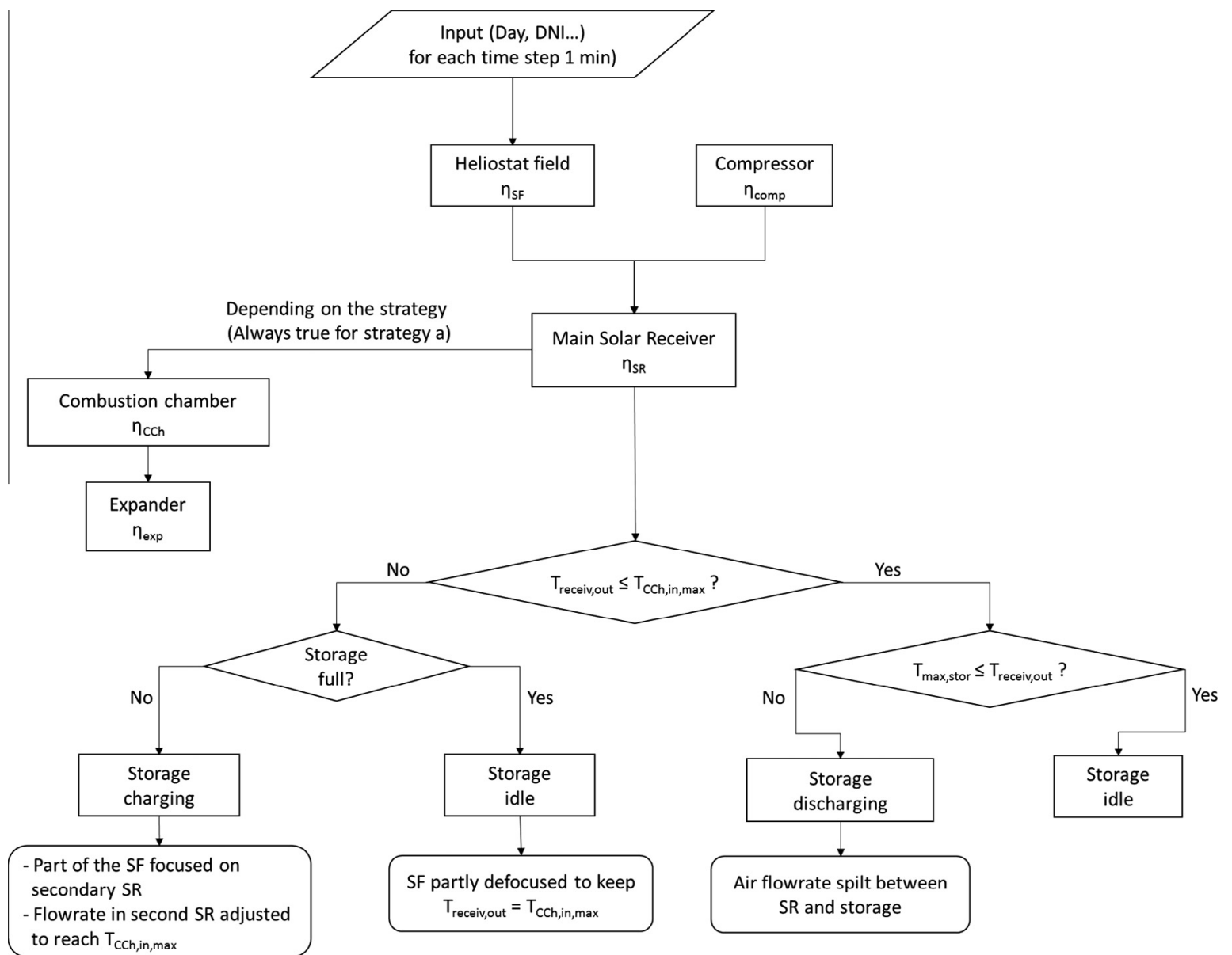

Fig. 4. Flowchart of the HSGTPP with integration of TES. 
Table 3

Nominal operating condition of the HSGTPP.

\begin{tabular}{|c|c|c|}
\hline & Atmospheric pressure (bar) & 0.85 \\
\hline & Nominal mass flow rate $(\mathrm{kg} / \mathrm{s})$ & 7.94 \\
\hline & Actual nominal mass flow-rate $(\mathrm{kg} / \mathrm{s})$ & 6.6 \\
\hline & $\begin{array}{l}\text { Pressure losses coefficient within pipes (- } \\
\text { ) }\end{array}$ & 1 \\
\hline \multirow[t]{2}{*}{ Compressor } & Compression rate $(-)$ & 9.6 \\
\hline & Isentropic efficiency (-) & 0.85 \\
\hline \multirow[t]{5}{*}{ Solar receiver } & Pressure losses coefficient (-) & $\begin{array}{l}\text { Cf. } \\
\text { Section } 3.2\end{array}$ \\
\hline & Nominal mass flow rate $(\mathrm{kg} / \mathrm{s})$ & 8 \\
\hline & Efficiency (-) & Cf. \\
\hline & & Section 3.2 \\
\hline & Maximal air outlet temperature $\left({ }^{\circ} \mathrm{C}\right)$ & 750 \\
\hline \multirow[t]{4}{*}{ Solar field } & $\begin{array}{l}\text { Number of heliostat (without or with } \\
\text { storage) }\end{array}$ & 104 or 208 \\
\hline & Surface of heliostat $\left(\mathrm{m}^{2}\right)$ & 54 \\
\hline & Efficiency (-) & \\
\hline & & Section 3.2 \\
\hline \multirow[t]{7}{*}{ Storage } & Initial temperature $\left({ }^{\circ} \mathrm{C}\right)$ & 300 \\
\hline & Nominal mass flow rate $(\mathrm{kg} / \mathrm{s})$ & 8 \\
\hline & $\begin{array}{l}\text { Discharge time at the nominal mass flow } \\
\text { rate }(h)\end{array}$ & 5 \\
\hline & Pressure losses coefficient $(-)$ & Cf. Eq. (3) \\
\hline & Height of the tank (m) & 15 \\
\hline & Diameter of the tank (m) & 3 \\
\hline & Particle diameter $(\mathrm{m})$ & 0.02 \\
\hline Blower & Isentropic efficiency & 0.85 \\
\hline \multirow{6}{*}{$\begin{array}{c}\text { Combustion } \\
\text { chamber }\end{array}$} & Maximal air inlet temperature $\left({ }^{\circ} \mathrm{C}\right)$ & 750 \\
\hline & Target air outlet temperature $\left({ }^{\circ} \mathrm{C}\right)$ & 1035 \\
\hline & Pressure losses coefficient $(-)$ & 0.96 \\
\hline & Combustion efficiency $(-)$ & 1 \\
\hline & Fuel temperature at the inlet $\left({ }^{\circ} \mathrm{C}\right)$ & 25 \\
\hline & Type of fuel & Methane \\
\hline Expander & Isentropic efficiency (-) & 0.89 \\
\hline \multirow[t]{2}{*}{ Chimney } & Pressure losses coefficient (-) & 0.98 \\
\hline & Pressure at the outlet (bar) & 0.85 \\
\hline \multirow[t]{2}{*}{ Gas turbine shaft } & Losses shaft/compressor (-) & 0 \\
\hline & Losses shaft/turbine $(-)$ & 0 \\
\hline Generator & Efficiency (-) & 0.97 \\
\hline
\end{tabular}

\section{Results}

Table 3 presents the features of the HSGTPP components. Although the nominal air mass flow-rate is $7.94 \mathrm{~kg} / \mathrm{s}$, the actual nominal mass flow-rate drops down to $6.6 \mathrm{~kg} / \mathrm{s}$ due to a lower atmospheric pressure at the THEMIS site, which is located at $1650 \mathrm{~m}$ of altitude.

As an example, the following results are obtained for a HSGTPP with a TES unit, a sunny day and a $24 \mathrm{~h} / 24 \mathrm{~h}$ electrical production. Fig. 5a shows the mass flow-rates through the power plant components and Fig. 5b presents the power amount provided by the receiver, the storage and the combustion chamber. Moreover Fig. 5c specifies how many heliostats are focused on the main and on the secondary solar receiver. To distinguish the charging and discharging modes, the mass flow rate through the storage and the power amount within the storage are negative during the charging phase and positive during the discharging phase.

In the early morning, the DNI is equal to zero and the storage is empty. The storage is idle and the plant operates in the fossil-only mode. From 7:30 a.m. to 8:30 a.m., the solar contribution to the heat provided to the fluid increases, while the fossil contribution decreases accordingly. During this period, the DNI is not high enough to reach $750{ }^{\circ} \mathrm{C}$ at the solar receiver outlet. Consequently the storage remains idle.

At 8:30 a.m. the DNI is high enough to partly focus the heliostat field on the secondary solar receiver. Therefore the storage is in charging phase, with a flow-rate increasing with the DNI until 10:30 a.m. when it reaches its nominal value. From 10:30 a.m. to 3:15 p.m., a small part of the heliostat field is defocused to keep the air outlet temperature of $750{ }^{\circ} \mathrm{C}$ in both solar receivers. It shows that the heliostat field design is successful. Although an ideal design would result in the use of all heliostats all day long, some additional heliostats allow the operation of the power plant in case of heliostat's maintenance. After 3:15 p.m., more and more heliostats aim back at the main solar receiver to keep the target temperature at the outlet of the main solar receiver while the DNI decreases. At 5:30 p.m. all the heliostat field focuses on the main solar receiver and the storage discharging starts, replacing gradually the main receiver solar contribution. At 6:45 p.m. all the mass flow-rate delivered by the compressor go through the storage. At 10:30 p.m. the storage contribution decreases more and more, while the fossil contribution increases accordingly. Finally the storage is empty and the plant operates in the fossilonly mode.

Fig. 6 presents the temperature profile in the storage tank in the same conditions as before.

The solid temperature profile increases gradually until 5:30 p. $\mathrm{m}$., when the lowest temperature (at the bottom of the tank) is around $375^{\circ} \mathrm{C}$, validating the design of the TES unit.

Fig. 7 compares the thermodynamic efficiency for a HSGTPP without and with a TES unit, operating $24 \mathrm{~h} / 24 \mathrm{~h}$ during a sunny day. The thermodynamic efficiency is the mechanical work delivered by the cycle over the heat provided to the fluid. The mechanical work delivered by the cycle is the work provided by the expander minus the work consumed by the compressor. The heat provided to the fluid is the sum of the enthalpy gained in the solar receiver, in the combustion chamber and during the storage discharge phase.

At 7:00 a.m., both power plants operate in the fossil-only mode, the main solar receiver is by-passed and the efficiency is almost $30 \%$ due to a higher mass flow-rate in the expander coming from the smokes leaving the combustion chamber. At sunrise, the fluid passes through the main solar receiver and the efficiency decreases because of the pressure drop in the receiver. While the DNI increases, the efficiency of the HSGTPP with storage rises faster than the one without storage. This comes from the larger heliostat field of the HSGTPP with storage, causing a greater air temperature at the outlet of the receiver. From 8:30 a.m. to 5:30 p.m., both efficiencies are similar as the storage charging does not have any impact on the power plant performance.

At 5:30 p.m., the efficiency of the HSGTPP without storage decreases with the DNI. At 6:30 p.m., the solar incident power is too low and the main solar receiver is by-passed, which results in an increase of the efficiency due to the higher amount of smokes from the combustion chamber. With the HSGTPP with storage, the efficiency is constant between 5:30 p.m. and 6:30 p.m. because the storage discharging allows keeping an air temperature of $750{ }^{\circ} \mathrm{C}$ at the inlet of the combustion chamber. At 6:30 p.m., the efficiency considerably increases since all the air coming from the compressor passes through the storage and endures less pressure drop. While the storage is discharged, the efficiency increases with the amount of fuel injected in the combustion chamber, hence the smokes leaving the combustion chamber. Finally at 2:00 p.m., the FAR upper limit is reached and the inlet temperature of the expander cannot be maintained, leading to a lower efficiency. It can be noticed that at 5:30 a.m., the efficiency of the HSGTPP with storage is lower than the one without storage. It is explained by the fact that the air passes through the storage unit as long as a positive heat amount is provided to the fluid. However this heat amount is very low and does not offset the pressure drop in the storage. A storage by-pass can be integrated in the power plant to overcome this issue. 

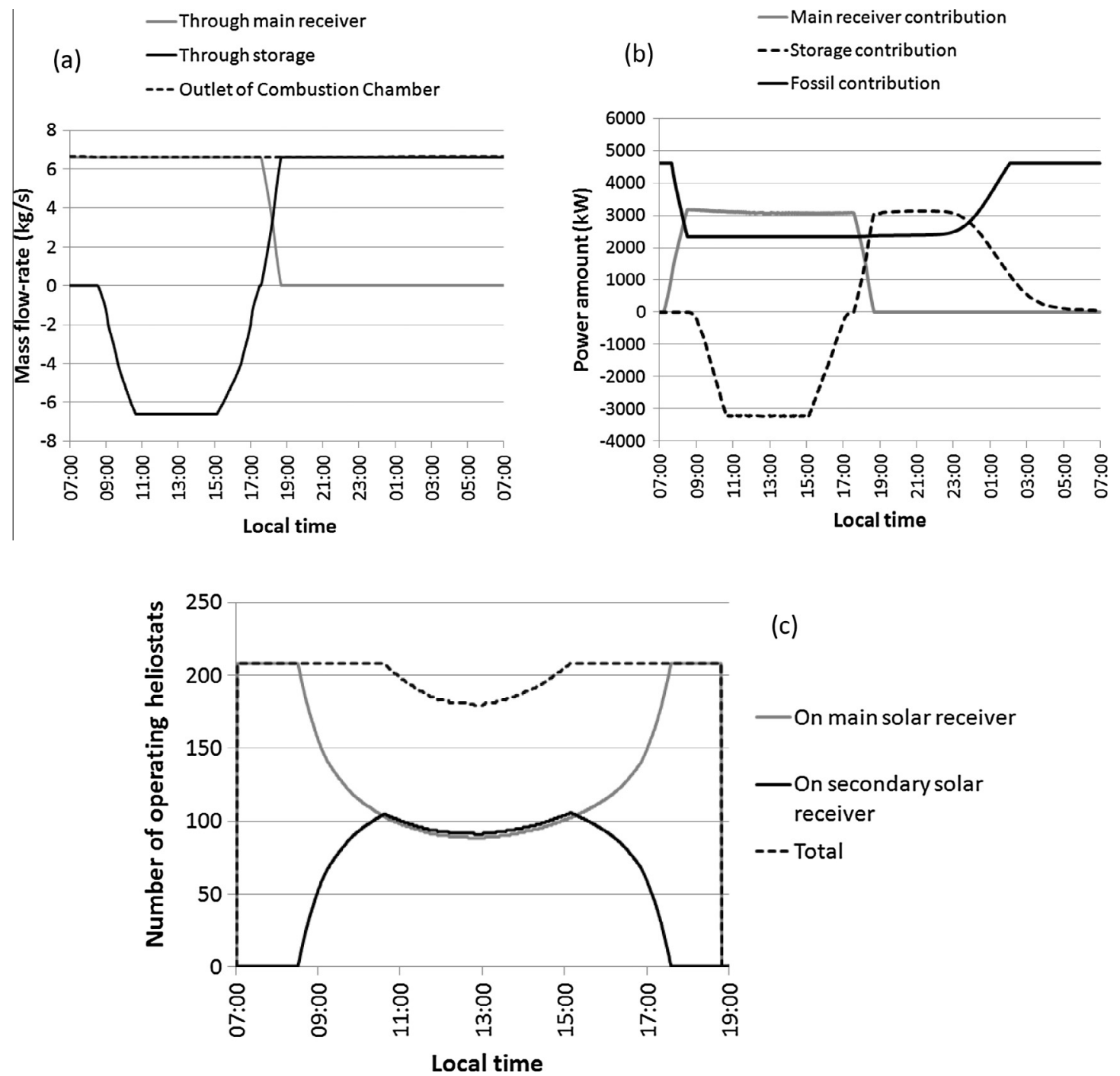

(c)

_On main solar receiver

-On secondarysolar

receiver

--- Total

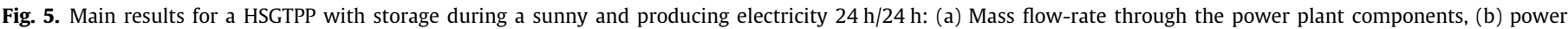
amount delivered to the fluid and (c) number of operating heliostats.

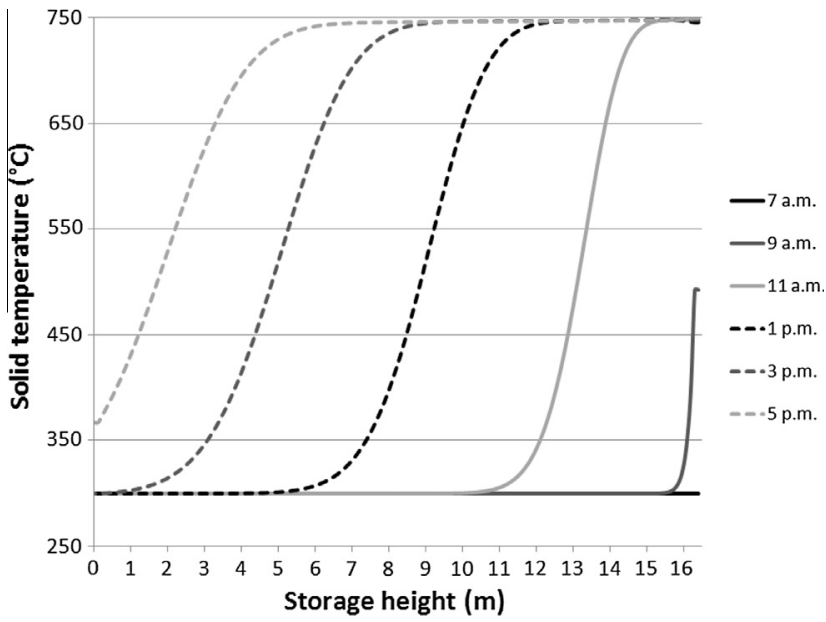

Fig. 6. Temperature profile in the TES unit.

The performance's parameters of the HSGTPP, defined in Section 3.1, are illustrated in Fig. 8. Their value depends on the

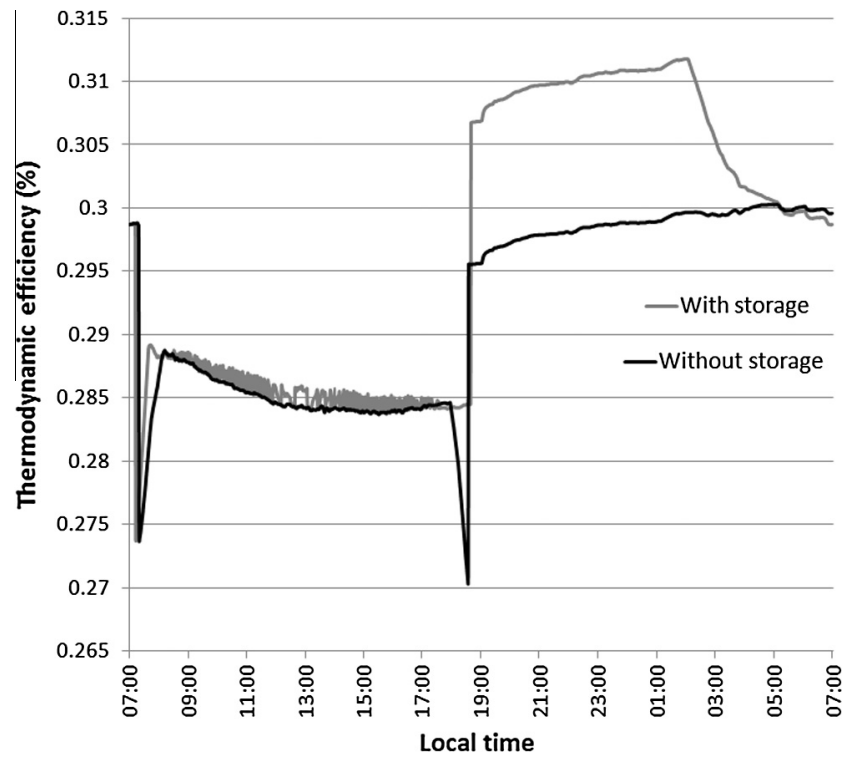

Fig. 7. Comparison of the thermodynamic efficiency for a HSGTPP without and with a TES unit. 

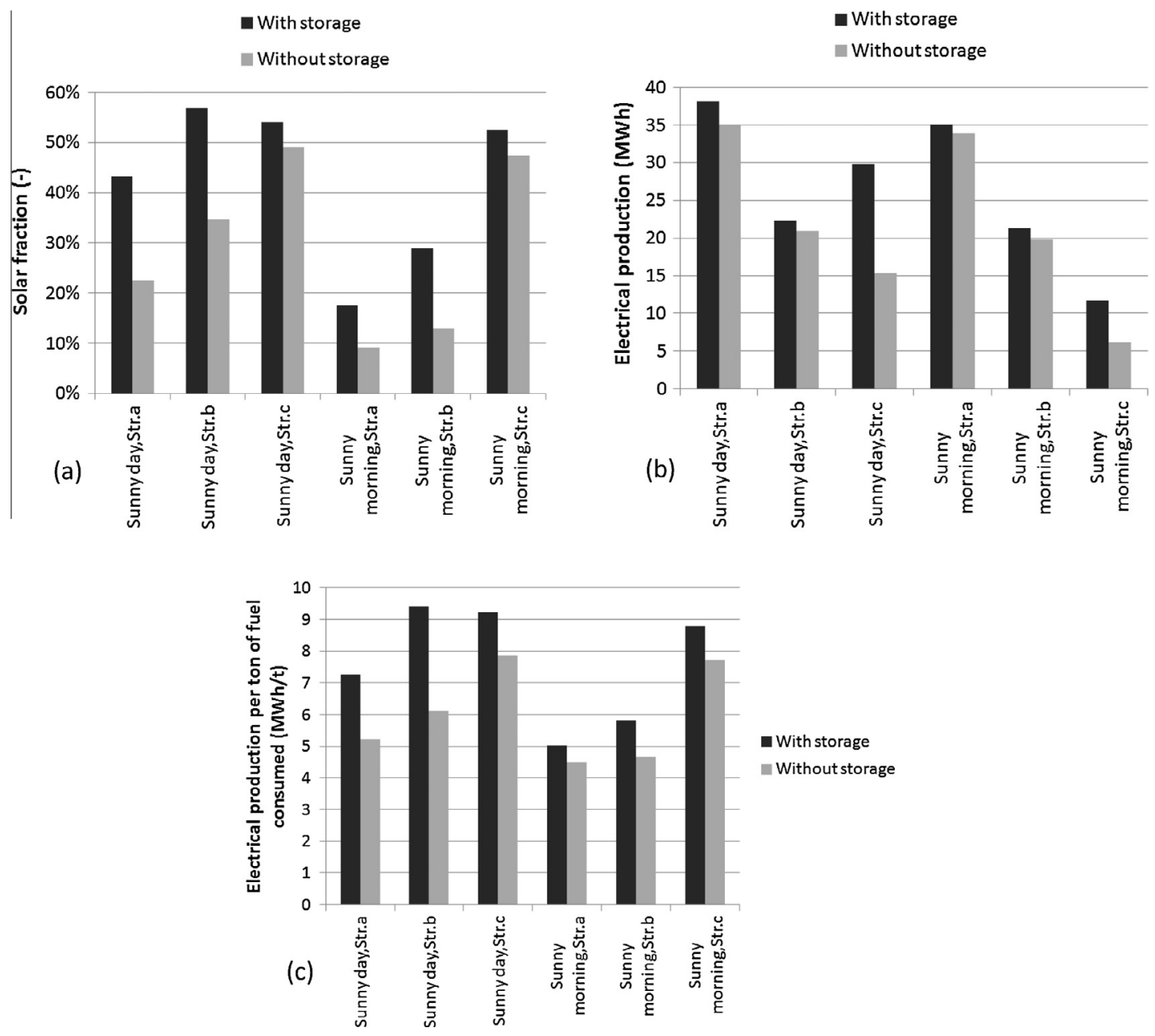

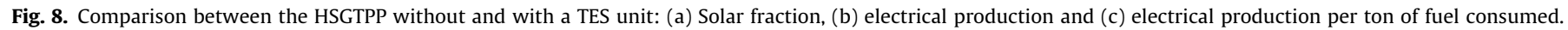

storage existence, the plant strategy (Cf. Section 4.1) and the DNI variation (Cf. Section 4.2).

By considering a $24 \mathrm{~h} / 24 \mathrm{~h}$ electrical production (strategy a), the solar fraction is doubled when a TES unit is integrated, for a sunny day or a sunny morning. However the electrical production is quite similar. The storage offers an EPTFC increase of $40 \%$ during a sunny day, but only $10 \%$ during a sunny morning. By operating the HSGTPP with strategy b, the comparison is quite similar. However compared to a $24 \mathrm{~h} / 24 \mathrm{~h}$ electrical production, this strategy offers a higher solar fraction as well as a higher EPTFC and obviously a lower electrical production. For a HSGTPP operating when the nominal air temperature at the inlet of the expander is reached (strategy c), the main influence of the storage is observed on the electrical production which is almost doubled. For both DNI variations, the storage allows increasing the solar fraction by $10 \%$ and the EPTFC by $15 \%$.

\section{Conclusion}

The solar fraction benefits from the integration of a TES unit for a base-load electrical production (strategy a) and a load following power plant (strategy b). Similarly the storage allows an increase of the EPTFC, but especially for a sunny day. Indeed with a sunny morning, the storage does not have enough time to be charged. The storage does not enhance considerably the electrical production for these two strategies, but has an important influence when the power plant operates only if the nominal inlet temperature in the expander is reached (strategy c).
Other architectures of HSGTPP with a TES unit must be compared with the one suggested in this paper in order to enhance as much as possible the performance of the power plant.

Finally a simple Brayton cycle is examined in this paper, leading to thermodynamic efficiency around 30\%. However higher thermodynamic efficiency can be obtained by considering a recuperator or a combined cycle HSGTPP. Improvements on the model must be undertaken to carry out this study.

\section{Acknowledgements}

This work was supported by the French "Investments for the future" program managed by the French National Agency for Research under contracts ANR-10-LABX-22-01 (SOLSTICE).

\section{References}

[1] H.L. Zhang, J. Baeyens, J. Degreve, G. Caceres, Concentrated solar power plants: review and design methodology, Renew. Sustain. Energy Rev. 22 (2013) 466481.

[2] M. Medrano et al., State of the art on high-temperature thermal energy storage for power generation. Part 2: case studies, Renew. Sustain. Energy Rev. 14 (2010) 56-72.

[3] U. Fisher et al., Gas-turbine "solarization" - modifications for solar/fuel hybrid operation, Sol. Energy Eng. 126 (2004) 872-878.

[4] E.F. Camacho, F.R. Rubio, M. Berenguel, L. Valenzuela, A survey on control schemes for distributed solar collector fields. Part I: modeling and basic control approaches, Sol. Energy 81 (2007) 1240-1251.

[5] E.F. Camacho, F.R. Rubio, M. Berenguel, L. Valenzuela, A survey on control schemes for distributed solar collector fields. Part II: advanced control approaches, Sol. Energy 81 (2007) 1252-1272. 
[6] T. Stuetzle, N. Blair, J.W. Mitchell, W.A. Beckman, Automatic control of a 30 MWe SEGS VI parabolic trough plant, Sol. Energy 76 (2004) 187-193.

[7] P. Denholm, M. Mehos, Enabling Greater Penetration of Solar Power via the Use of CSP with Thermal Energy Storage, Technical Report NREL/TP-6A20-52978 November, 2011.

[8] A. Gil et al., State of the art on high temperature thermal energy storage for power generation. Part 1 - concepts, materials and modellization, Renew. Sustain. Energy Rev. 14 (2010) 31-55.

[9] K.M. Powell, T.F. Edgar, Modeling and control of a solar thermal power plant with thermal energy storage, Chem. Eng. Sci. 71 (2012) 138-145.

[10] J. Spelling, R. Guédez, B. Laumert, A thermo-economic study of storage integration in hybrid solar gas-turbine power plants, J. Sol. Energy Eng 137 (1) (2014) 10.

[11] S. Relloso, J. Lata, Molten salt thermal storage: a proven solution to increase plant dispatchability. Experience in Gemasolar power plant, in: Proceedings of 17th SolarPACES Symposium, Granada, Spain, 2011.

[12] M.J. Wagner, G. Zhu, A generic CSP performance model for NREL's System Advisor Model, in: Proceedings of 17th SolarPACES Symposium, Granada Spain, 2011.
[13] S. Giuliano, R. Buck, S. Eguiguren, Analysis of solar thermal power plants with thermal energy storage and solar hybrid operation strategy, in: Proceedings of 17th SolarPACES Symposium, Granada, Spain, 2011.

[14] P Garcia, Codes for Solar Flux Calculation Dedicated to Central Receiver System Applications PhD thesis, University of Perpignan, France, 2007.

[15] M. Grange, Modeling and Design of a Pressurized Air Solar Receiver for the PEGASE Project PhD thesis, University of Perpignan, France, 2012.

[16] R.P. Zou, A.B. Yu, The packing of spheres in a cylindrical container: the thickness effect, Chem. Eng. Sci. 50 (1995) 1504-1507.

[17] M. Hänchen et al., High-temperature thermal storage using a packed bed of rocks - heat transfer analysis and experimental validation, Appl. Therm. Eng. 31 (2011) 1798-1806.

[18] M. Vrinat, Development of a High Temperature Air Solar Receiver Based on Compact Heat Exchanger Technology PhD thesis, University of Perpignan, France, 2010.

[19] Meherwan P. Boyce, Gas Turbine Engineering Handbook, third ed., Gulf Professionnal Publishing, 2006. 